\title{
Different kinds of vegetable oils in relation to individual cardiovascular risk factors among Iranian women
}

\author{
Ahmad Esmaillzadeh ${ }^{1,2 *}$ and Leila Azadbakht ${ }^{1,2}$ \\ ${ }^{1}$ Department of Nutrition, School of Public Health, Isfahan University of Medical Sciences, PO Box 81745, Isfahan, Iran \\ ${ }^{2}$ Food Security and Nutrition Research Center, Isfahan University of Medical Sciences, Isfahan, Iran
}

(Received 5 September 2009 - Revised 2 September 2010 - Accepted 24 September 2010 - First published online 21 January 2011)

\section{Abstract}

Detrimental effects of trans-fats on lipid profiles, blood pressure and plasma glucose levels have been documented by short-term clinical trials with high doses of trans-fats, but limited observational studies have considered habitual consumption of partially hydrogenated vegetable oil (PHVO) and these outcome variables, particularly hypertension. We aimed to evaluate the association of PHVO and nonhydrogenated vegetable oils (non-HVO) intake with individual cardiovascular risk factors. In a cross-sectional study of 486 Iranian adult women, usual dietary intakes were assessed, and fasting plasma glucose (FPG), lipid profiles and blood pressure were measured. PHVO (commonly used for cooking in Iran) were considered as the PHVO category. Sunflower oil, maize oil, rapeseed oil, soyabean oil and olive oil were defined as the non-HVO category. Diabetes (FPG $\geq 1260 \mathrm{mg} / \mathrm{l}$ ), dyslipidaemia (based on Adult Treatment Panel III) and hypertension (based on Joint National Committee VI) were defined. The presence of 'at least one risk factor' and 'at least two risk factors' of the three major risk factors for CVD (hypertension, dyslipidaemia and diabetes) was also evaluated. After controlling for age and other potential confounders, a high consumption of HVO was associated with a greater risk of having dyslipidaemia (OR for top $v$. bottom quintile 5.04; 95\% CI 2·70, 9.36), hypertension (OR for top $v$. bottom quintile 3.03; 95\% CI 1.55, 6.10), at least one (OR for top $v$. bottom quintile 8.52; $95 \%$ CI 4.41, 16.41) and at least two risk factors (OR for top $v$. bottom quintile 3.60; $95 \%$ CI $1.64,7.74)$, while those in the top quintile of non-HVO consumption had lower odds for all these conditions. Further adjustment for dietary intakes had little impact on these associations. Even after additional adjustment for BMI, the positive association of HVO and the inverse association of non-HVO with the above-mentioned cardiovascular risk factors remained significant, except for the association between non-HVO and hypertension that became marginally significant. No overall significant associations were found between the consumption of HVO and non-HVO and diabetes. Higher intakes of PHVO were associated with a greater risk of individual cardiovascular risk factors, while those of non-HVO were associated with a reduced risk.

\section{Key words: Partially hydrogenated vegetable oils: CVD: trans-Fatty acids: Women}

CVD is among the world's leading causes of death, with nearly $80 \%$ of deaths occurring in developing countries ${ }^{(1)}$. Although cardiovascular death rates have significantly declined in most developed countries in the past decades, rates have grown in developing countries ${ }^{(2)}$, such that $25-45 \%$ of total deaths in these countries can be explained by $\mathrm{CVD}^{(3)}$. Furthermore, it seems that people in developing countries experience coronary artery disease at a younger age than those in Western countries ${ }^{(4)}$. Therefore, identification of the determinants of cardiovascular risk factors is of particular importance in these countries.

Dietary fat intake has long been the source of interest in cardiovascular health. Among the different types of dietary fats, trans-fatty acids (TFA) are of high interest ${ }^{(5)}$. Besides their natural dietary sources ${ }^{(6)}$, these fatty acids are formed during the partial hydrogenation of vegetable oils. Relative to unsaturated fatty acids, the intake of TFA results in higher LDL-cholesterol (LDL-C) concentrations, and relative to saturated fat, the intake of TFA results in lower HDL-cholesterol (HDL-C) concentrations ${ }^{(7,8)}$. A higher consumption of TFA has also been associated with an increased risk of developing $\mathrm{CVD}^{(9)}$ and type 2 diabetes ${ }^{(10)}$. However, most information available in this regard has mainly been derived from studies done in Western countries, and it is unclear to what extent these findings apply to developing countries, as some data suggest that risk factors for CVD vary greatly between populations $^{(2)}$. Furthermore, the detrimental effects of trans-fats on lipid profiles, blood pressure and plasma glucose levels have been documented by short-term

Abbreviations: HDL-C, HDL-cholesterol; HVO, hydrogenated vegetable oils; LDL-C, LDL-cholesterol; PHVO, partially HVO; TFA, trans-fatty acids. 
clinical trials with high doses of trans-fats, but limited observational studies have considered habitual consumption of partially hydrogenated vegetable oils (PHVO) and these outcome variables. This is particularly relevant for hypertension, where we have not found any observational study assessing PHVO in relation to blood pressure.

The average per-person home use of PHVO among Iranians is $14 \mathrm{~g} / 4184 \mathrm{~kJ}(1000 \mathrm{kcal})^{(11)}$, with almost $33 \%$ of fatty acids in these products as $\mathrm{TFA}^{(12)}$. Therefore, Iranians take $4.2 \%$ of their energy from TFA, almost twice the amount in developed countries ${ }^{(11)}$. Such dietary intakes might help to explain the high prevalence of cardiovascular risk factors, particularly high serum TAG levels and low serum HDL-C concentrations, among the Iranian population compared with that in Western populations ${ }^{(13)}$. In the framework of dietary pattern analysis, we have shown that those with greater adherence to the Western and Iranian dietary patterns (both greatly loaded with PHVO) were more likely to have cardiovascular risk factors $^{(14)}$. Furthermore, our previous investigations have demonstrated that consumption of hydrogenated vegetable oils (HVO) is independently associated with a greater risk of insulin resistance, the metabolic syndrome, elevated levels of markers of inflammation and endothelial dysfunction $^{(15,16)}$. In the present study, we aimed to evaluate the association of PHVO and non-HVO intake with individual cardiovascular risk factors.

\section{Subjects and methods}

\section{Participants}

Detailed information about the population and the measurements done can be found elsewhere ${ }^{(17-19)}$. Briefly, in the present cross-sectional study, performed among a representative sample of Tehrani female teachers aged 40-60 years, a total of 583 female teachers, selected by a multistage cluster random sampling method, were invited to participate and 521 women agreed (response rate: $89 \%$ ). To have a representative sample of female teachers, we divided twenty districts of Tehran Educational Offices into four categories (northern, western, southern and eastern parts of the city) because socio-economic variables are different in these four parts and dietary intakes of people living in these different parts might differ. Then, we randomly selected four districts (one from each category) of Tehran Educational Offices (districts 1, 9, 12 and 16). We obtained the list of schools (separately for public and private schools) and list of female teachers working in each district. Considering the number of public and private schools in each district, we randomly selected sixty-three schools (sixteen schools from district 1, seventeen schools from district 9, fourteen schools from district 12 and sixteen schools from district 16). The required number of female teachers was randomly selected proportionally to size in each district and school (131 women from district 1, 140 women from district 9, 113 women from district 12 and 137 women from district 16). After excluding women with a prior history of CVD, diabetes, cancer and stroke, those who had left $>$ seventy items blank on the FFQ, those who reported a total daily energy intake outside the range of $3344-17556 \mathrm{~kJ}(800-4200 \mathrm{kcal})$ and those taking medications that would affect serum lipoprotein, blood pressure and carbohydrate metabolism, 486 women remained for the present analysis. The whole project was approved by the Ethical Committee of the National Nutrition and Food Technology Research Institute, Shaheed Beheshti University of Medical Sciences. Informed written consent was obtained from each participant. The present study was conducted according to the guidelines laid down in the Declaration of Helsinki.

\section{Measurements}

Usual dietary intakes were assessed by a trained dietitian using a validated semi-quantitative FFQ that consisted of a list of 168 food items with a standard serving size ${ }^{(15)}$. The frequency of consumption of a given serving of each food item during the previous year on a daily, weekly or monthly basis was asked. However, the reported frequencies were then converted to $\mathrm{g} / \mathrm{d}$ using standard published guidelines $^{(20)}$. PHVO (commonly used for cooking in Iran) was considered as the PHVO category. Sunflower oil, maize oil, rapeseed oil, soyabean oil and olive oil were defined as the non-HVO category. We did not collect data on the type of hydrogenated products that the participants consumed. Our FFQ included type of nonHVO individually, but only one item in our FFQ was about PHVO. Therefore, we were unable to describe the variety of PHVO consumed. However, the blending of oil from different sources, including sunflower, soyabean and other vegetable oils, to produce PHVO is a common practice in the developing world.

Weight, height and waist circumference were measured according to standard protocols, as described earlier ${ }^{(19)}$, and BMI was calculated. After a $12 \mathrm{~h}$ overnight fast, the blood sample was drawn for biochemical assessment. As described elsewhere in more detail ${ }^{(17,18)}$, the analysis of samples was performed using a Selectra 2 auto-analyser (Vital Scientific, Spankeren, The Netherlands). Fasting plasma glucose was measured on the day of blood collection by an enzymatic colorimetric method using glucose oxidase (Pars Azmoon, Inc., Tehran, Iran). Serum TAG concentrations were assayed using TAG kits (Pars Azmoon, Inc.) by enzymatic colorimetric tests with glycerol phosphate oxidase ${ }^{(21)}$. Serum HDL-C was measured after the precipitation of apoB-containing lipoproteins with phosphotungstic acid. Serum LDL-C was calculated from serum total cholesterol, TAG and HDL-C, except when the TAG concentration was greater than $4.4 \mathrm{mmol} / 1$ $(4000 \mathrm{mg} / \mathrm{l})^{(22)}$. The inter- and intra-assay $\mathrm{CV}$ of this method were $<10 \%$. Blood pressure was measured three 
times after the participants sat for $15 \mathrm{~min}$, as reported earlier ${ }^{(17,18)}$. Hypertriacylglycerolaemia was defined as serum TAG $\geq 2.2 \mathrm{mmol} / 1(2000 \mathrm{mg} / \mathrm{l})$, hypercholesterolaemia as serum total cholesterol $\geq 6.24 \mathrm{mmol} / 1 \quad(2400 \mathrm{mg} / \mathrm{l})$, high serum LDL-C as $\geq 4.1 \mathrm{mmol} / 1(1600 \mathrm{mg} / \mathrm{l})$ and low serum HDL-C as $<1.29 \mathrm{mmol} / \mathrm{l} \quad\left(500 \mathrm{mg} / \mathrm{l}^{(23)}\right.$. Dyslipidaemia was defined based on the third report of the National Cholesterol Education Program Expert Panel $^{(23)}$ as having hypertriacylglycerolaemia, hypercholesterolaemia, high LDL-C or low HDL-C. Hypertension was defined as systolic blood pressure $\geq 140 \mathrm{mmHg}$ or diastolic blood pressure $\geq 90 \mathrm{mmHg}$ based on Joint National Committee $\mathrm{VI}^{(24)}$. Diabetes mellitus was defined as fasting plasma glucose $\geq 6.93 \mathrm{mmol} / 1(1260 \mathrm{mg} / \mathrm{l})^{(25)}$. The presence of 'at least one risk factor' and 'at least two risk factors' of the three major risk factors for CVD (hypertension, dyslipidaemia and diabetes) was also evaluated. Data on physical activity, reported earlier in more detail ${ }^{(26)}$, were obtained using the International Physical Activity Questionnaire ${ }^{(27)}$ and expressed as metabolic equivalent-h/week. Additional covariate information regarding age, smoking habits, socio-economic status, medical history and current use of medications was obtained using questionnaires.

\section{Statistical methods}

First, we applied a residual method ${ }^{(28)}$ to obtain energyadjusted intakes of PHVO and non-HVO. Then, participants were categorised based on quintiles of energy-adjusted intakes of PHVO or non-HVO to reduce misclassification. ANOVA with Tukey's post hoc comparisons and $\chi^{2}$ tests were used to compare continuous and categorical variables, respectively, across quintiles. Dietary intakes of participants across quintiles of $\mathrm{PHVO}$ and non-HVO were assessed using ANCOVA, with age and energy as covariates. To obtain multivariate-adjusted means for cardiovascular risk factors across quintiles of $\mathrm{PHVO}$ and non-HVO, we controlled for the mutual effects of $\mathrm{HVO}$ and non-HVO $(\mathrm{g} / \mathrm{d})$, age (years), energy intakes $(\mathrm{kJ} / \mathrm{d})$, cigarette smoking (yes or no), physical activity (metabolic equivalent-h/week), socio-economic status (categorical), current oestrogen use (yes or no), menopausal status (yes or no) and family history of diabetes and stroke (yes or no) in the first model; further adjusted for dietary intakes (including intakes of cholesterol, fruits and vegetables, whole and refined grains, dairy, meat, fish and poultry all as continuous) in the second model; and additionally for BMI (continuous) in the final model to observe whether the associations are mediated by obesity. Multinomial logistic regression analyses (with the abovementioned covariates) were used to calculate adjusted OR and $95 \%$ CI by considering the sampling design. In all multivariate models, the first quintile was considered as the reference. The overall trend of OR was computed using the Mantel-Haenszel extension $\chi^{2}$ test. $P<0.05$ was considered as significant. All statistical analyses were performed using SPSS (version 16.0; SPSS, Inc., Chicago, IL, USA).

\section{Results}

Mean energy-adjusted daily intakes of PHVO and nonHVO were 23 (SD 11) and 22 (SD 10) g/d, respectively. Characteristics of the study participants across quintile categories of PHVO and non-HVO are shown in Table 1. Those in the upper quintile of HVO had a higher age, BMI and waist-to-hip ratio and were more likely to be postmenopausal, while those in the upper quintile of non-HVO were younger and were more likely to have a family history of diabetes compared with those in the lowest quintile. There was no significant difference regarding the distribution of current smokers and obese people across quintile categories of either PHVO or non-HVO consumption. Those in the upper category of PHVO had higher intakes of cholesterol, while those in the top quintile of non-HVO had lower intakes of energy. Other nutrient intakes were not significantly different across quintile categories of either PHVO or non-HVO consumption. PHVO consumption was associated with higher intakes of high-fat dairy and lower intakes of low-fat dairy products, while non-HVO intake was associated with higher intakes of vegetables and low-fat dairy and lower intakes of high-fat dairy products.

Cardiovascular risk factors were more likely to be seen among individuals in the top quintile of PHVO intake compared with those in the lowest quintile (Table 2). In contrast, higher intakes of non-HVO were associated with a reduced prevalence of cardiovascular risk factors. The prevalence of diabetes across quintiles of $\mathrm{PHVO}$ and non-HVO consumption was not significantly different.

After controlling for age and other potential confounders, individuals in the top quintile of PHVO consumption had significantly higher concentrations of serum TAG, total- and LDL-C, elevated diastolic blood pressure and lower levels of serum HDL-C compared with those in the lowest quintile (data not shown). Further adjustment for dietary intakes including energy intake attenuated the associations. Even after further adjustment for BMI, the positive association of HVO consumption with serum TAG, total-, LDL- and HDL-C levels remained significant. Those in the highest quintile of non-HVO consumption had lower levels of serum TAG, total- and LDL-C, and higher levels of serum HDL-C compared with those in the lowest quintile. Further adjustment for dietary intakes removed the significant associations with serum HDL-C concentrations. However, even after additional adjustment for BMI, the inverse association with serum TAG and LDL-C levels remained significant (data not shown).

Multivariate-adjusted OR for individual cardiovascular risk factors across quintile categories of PHVO and non-HVO consumption are presented in Table 3. After controlling for age and other potential confounders, a 
Table 1. Characteristics of the study participants by quintiles of energy-adjusted amounts of partially hydrogenated (PHVO) and non-hydrogenated vegetable oils (HVO)* (Mean values and standard deviations or percentages)

\begin{tabular}{|c|c|c|c|c|c|c|c|c|c|c|c|c|c|c|c|c|c|c|c|c|c|c|}
\hline & \multicolumn{10}{|c|}{ PHVO quintiles } & \multirow[b]{3}{*}{$P \dagger$} & \multicolumn{10}{|c|}{ Non-HVO quintiles } & \multirow[b]{3}{*}{$P \dagger$} \\
\hline & \multicolumn{2}{|c|}{1} & \multicolumn{2}{|l|}{2} & \multicolumn{2}{|l|}{3} & \multicolumn{2}{|c|}{4} & \multicolumn{2}{|l|}{5} & & \multicolumn{2}{|c|}{1} & \multicolumn{2}{|c|}{2} & \multicolumn{2}{|c|}{3} & \multicolumn{2}{|c|}{4} & \multicolumn{2}{|l|}{5} & \\
\hline & Mean & SD & Mean & SD & Mean & SD & Mean & SD & Mean & SD & & Mean & SD & Mean & SD & Mean & SD & Mean & SD & Mean & SD & \\
\hline$n$ & \multicolumn{2}{|c|}{97} & \multicolumn{2}{|c|}{97} & \multicolumn{2}{|c|}{97} & \multicolumn{2}{|c|}{98} & \multicolumn{2}{|c|}{97} & & \multirow{2}{*}{\multicolumn{2}{|c|}{$\begin{array}{c}97 \\
<14.7\end{array}$}} & \multicolumn{2}{|c|}{97} & \multicolumn{2}{|c|}{98} & 97 & & 97 & & \\
\hline Range (g/d) & $<12$ & & $12.7-<$ & 17.8 & $17 \cdot 8-<$ & $27 \cdot 1$ & $27 \cdot 1-<$ & 32.6 & $\geq 32$. & & & & & $14 \cdot 7-<$ & $19 \cdot 1$ & $19 \cdot 1-$ & $23 \cdot 4$ & $23.4-$ & $30 \cdot 1$ & $\geq 30$ & & \\
\hline Age (years) & 47 & 5 & 46 & 6 & 46 & 6 & 51 & 6 & 55 & 6 & 0.007 & 49 & 6 & 50 & 6 & 51 & 6 & 47 & 7 & 47 & 5 & 0.03 \\
\hline BMI $\left(\mathrm{kg} / \mathrm{m}^{2}\right)$ & 26.4 & 3.0 & $27 \cdot 2$ & $3 \cdot 1$ & 26.9 & 3.7 & 27.5 & 3.9 & 29.1 & 3.9 & 0.009 & $27 \cdot 1$ & 3.4 & 27.5 & 3.9 & 27.9 & 3.7 & 27.9 & 3.6 & 27.5 & 3.2 & 0.51 \\
\hline WHR & 0.85 & 0.08 & 0.88 & 0.08 & 0.85 & 0.08 & 0.86 & 0.07 & 0.92 & 0.08 & 0.01 & 0.87 & 0.08 & 0.87 & 0.08 & 0.86 & 0.07 & 0.86 & 0.09 & 0.88 & 0.07 & 0.48 \\
\hline $\begin{array}{l}\text { Physical activity } \\
\text { (MET-h/week) }\end{array}$ & $15 \cdot 1$ & $10 \cdot 8$ & 13.1 & $10 \cdot 8$ & $14 \cdot 9$ & $11 \cdot 0$ & $15 \cdot 0$ & $10 \cdot 1$ & $14 \cdot 2$ & $10 \cdot 4$ & 0.21 & 13.7 & $10 \cdot 6$ & $14 \cdot 2$ & $10 \cdot 2$ & $14 \cdot 4$ & $11 \cdot 3$ & 14.5 & 10.5 & $15 \cdot 5$ & 11.7 & 0.18 \\
\hline $\begin{array}{r}\text { Family history of } \\
\text { diabetes (\%) } \neq\end{array}$ & 10 & & 9 & & 8 & & 9 & & 10 & & 0.33 & 7 & & 9 & & 9 & & 10 & & 11 & & 0.04 \\
\hline $\begin{array}{l}\text { Family history of } \\
\text { stroke }(\%) \ddagger\end{array}$ & 1 & & 0 & & 1 & & 1 & & 2 & & 0.73 & 1 & & 1 & & 1 & & & & 1 & & 0.89 \\
\hline $\begin{array}{l}\text { Current daily } \\
\text { smokers (\%)‡ }\end{array}$ & 0 & & 1 & & 1 & & 0 & & 2 & & 0.29 & 1 & & 1 & & 0 & & & & 1 & & 0.78 \\
\hline Obese $(\%) \neq \S$ & 34 & & 36 & & 33 & & 33 & & 35 & & 0.53 & 3 & & 37 & & 38 & & 35 & & 32 & & 0.55 \\
\hline $\begin{array}{l}\text { Current oestrogen } \\
\text { use (\%) }\end{array}$ & 22 & & 24 & & 27 & & 24 & & 30 & & 0.03 & 26 & & 25 & & 23 & & 26 & & 28 & & 0.37 \\
\hline $\begin{array}{l}\text { Postmenopausal } \\
\text { (\%)‡ }\end{array}$ & 34 & & 38 & & 42 & & 55 & & 59 & & 0.008 & $5 c$ & & 42 & & 55 & & 40 & & 42 & & 0.22 \\
\hline Nutrients & & & & & & & & & & & & & & & & & & & & & & \\
\hline $\begin{array}{l}\text { Total energy } \\
(\mathrm{kJJ} / \mathrm{d}) \|\end{array}$ & $10196 \cdot 41$ & $100 \cdot 42$ & 10263.35 & 108.78 & $10305 \cdot 19$ & $121 \cdot 34$ & $10380 \cdot 50$ & $100 \cdot 42$ & 10137.83 & 87.86 & 0.489 & 9631.57 & 87.86 & 10899.32 & $104 \cdot 6$ & 10112.73 & 108.78 & 10506.02 & $104 \cdot 6$ & $10070 \cdot 89$ & 112.97 & 0.03 \\
\hline $\begin{array}{l}\text { Carbohydrate } \\
\text { (\% of total } \\
\text { energy) }\end{array}$ & 59 & 1 & 58 & 1 & 59 & 1 & 58 & 1 & 58 & 1 & 0.71 & 59 & 1 & 58 & 1 & 57 & 1 & 59 & 1 & 60 & 1 & 0.17 \\
\hline $\begin{array}{l}\text { Protein (\% of } \\
\text { total energy) }\end{array}$ & 12 & 0.6 & 13 & 0.6 & 13 & 0.5 & 13 & 0.5 & 12 & 0.5 & 0.90 & 13 & 0.9 & 14 & 0.8 & 14 & 0.7 & 14 & 0.8 & 12 & 0.6 & 0.44 \\
\hline $\begin{array}{l}\text { Fat (\% of total } \\
\text { energy) }\end{array}$ & 29 & 0.8 & 29 & 0.8 & 28 & 0.8 & 28 & 0.8 & 30 & 0.9 & 0.37 & 28 & 0.7 & 28 & 0.7 & 29 & 0.7 & 27 & 0.8 & 28 & 0.8 & 0.82 \\
\hline $\begin{array}{l}\text { Cholesterol } \\
\text { (mg/d) }\end{array}$ & 150 & 8 & 173 & 11 & 179 & 9 & 175 & 9 & 187 & 9 & 0.03 & 174 & 9 & 175 & 11 & 181 & 10 & 169 & 10 & 194 & 9 & 0.20 \\
\hline $\begin{array}{l}\text { Dietary fibre } \\
(\mathrm{g} / \mathrm{d})\end{array}$ & 13 & 1 & 14 & 1 & 15 & 1 & 16 & 1 & 16 & 1 & 0.11 & 14 & 1 & 16 & 1 & 14 & 1 & 15 & 1 & 16 & 1 & 0.63 \\
\hline Foods (g/d) & & & & & & & & & & & & & & & & & & & & & & \\
\hline PHVO & 10 & 1 & 14 & 1 & 24 & 1 & 31 & 1 & 36 & 1 & 0.007 & 35 & 1 & 21 & 1 & 22 & 1 & 24 & 1 & 16 & 1 & 0.008 \\
\hline Non-HVO & 33 & 1 & 26 & 1 & 24 & 1 & 17 & 1 & 12 & 1 & 0.001 & 13 & 1 & 16 & 1 & 21 & 1 & 25 & 1 & 36 & 1 & 0.003 \\
\hline Fruits & 221 & 7 & 231 & 8 & 229 & 8 & 223 & 8 & 228 & 9 & 0.64 & 237 & 8 & 217 & 7 & 215 & 8 & 227 & 8 & 224 & 7 & 0.49 \\
\hline Vegetables & 199 & 6 & 197 & 6 & 214 & 5 & 208 & 5 & 225 & 5 & 0.17 & 199 & 7 & 198 & 6 & 175 & 7 & 221 & 5 & 255 & 7 & 0.009 \\
\hline Meat and fish & 101 & 2 & 95 & 3 & 81 & 3 & 86 & 3 & 95 & 3 & 0.18 & 85 & 3 & 87 & 3 & 89 & 2 & 95 & 3 & 96 & 3 & 0.11 \\
\hline Whole grains & 121 & 3 & 127 & 3 & 111 & 3 & 110 & 2 & 119 & 2 & 0.37 & 119 & 2 & 118 & 4 & 110 & 3 & 115 & 3 & 118 & 3 & 0.58 \\
\hline Refined grains & 198 & 6 & 195 & 9 & 197 & 7 & 211 & 8 & 217 & 8 & 0.15 & 207 & 6 & 210 & 5 & 197 & 7 & 192 & 7 & 206 & 7 & 0.19 \\
\hline Low-fat dairy & 137 & 3 & 121 & 3 & 87 & 3 & 72 & 3 & 54 & 3 & 0.005 & 69 & 2 & 78 & 2 & 111 & 2 & 106 & 3 & 108 & 2 & 0.007 \\
\hline High-fat dairy & 86 & 3 & 86 & 2 & 87 & 3 & 107 & 2 & 111 & 3 & 0.03 & 120 & 2 & 104 & 3 & 99 & 3 & 90 & 3 & 65 & 3 & 0.001 \\
\hline
\end{tabular}

WHR, waist-to-hip ratio; MET, metabolic equivalent.

* Partially hydrogenated vegetable oil (PHVO, commonly used for cooking in Iran) was considered as the PHVO category. Sunflower oil, maize oil, rapeseed oil, soyabean oil and olive oil were defined as the non-HVO category. † By using ANOVA for continuous variables and the $\chi^{2}$ test for categorical variables.

$\ddagger$ Values are given in terms of percentages.

$\S$ Obesity: $\mathrm{BMI} \geq 30 \mathrm{~kg} / \mathrm{m}^{2}$.

$\| 4.2 \mathrm{~kJ}(1 \mathrm{kcal})=4.184 \mathrm{~kJ}$. 
Table 2. Prevalence of cardiovascular risk factors across quintiles of partially hydrogenated vegetable oil (PHVO) and non-hydrogenated vegetable oil $(\mathrm{HVO})^{*} \dagger$

\begin{tabular}{|c|c|c|c|c|c|c|c|c|c|c|c|c|}
\hline & \multicolumn{5}{|c|}{ PHVO quintiles (\%) } & \multicolumn{7}{|c|}{ Non-HVO quintiles (\%) } \\
\hline & $\begin{array}{c}1 \\
(n 97)\end{array}$ & $\begin{array}{c}2 \\
(n 97)\end{array}$ & $\begin{array}{c}3 \\
(n 97)\end{array}$ & $\begin{array}{c}4 \\
(n 98)\end{array}$ & $\begin{array}{c}5 \\
(n 97)\end{array}$ & $P \neq$ & $\begin{array}{c}1 \\
(n 97)\end{array}$ & $\begin{array}{c}2 \\
(n 97)\end{array}$ & $\begin{array}{c}3 \\
(n 98)\end{array}$ & $\begin{array}{c}4 \\
(n 97)\end{array}$ & $\begin{array}{c}5 \\
(n 97)\end{array}$ & $P \ddagger$ \\
\hline Diabetes & 3 & 5 & 6 & 6 & 7 & 0.31 & 9 & 6 & 5 & 3 & 4 & 0.19 \\
\hline Dyslipidaemia & 26 & 38 & 44 & 55 & 64 & 0.001 & 60 & 56 & 48 & 34 & 29 & 0.04 \\
\hline Hypertension & 17 & 25 & 26 & 29 & 38 & 0.03 & 33 & 33 & 27 & 23 & 19 & 0.03 \\
\hline At least one risk factor & 31 & 39 & 53 & 63 & 79 & 0.005 & 68 & 66 & 55 & 41 & 35 & 0.00 \\
\hline At least two risk factors & 11 & 12 & 18 & 23 & 32 & 0.04 & 35 & 27 & 15 & 12 & 7 & 0.00 \\
\hline
\end{tabular}

* Diabetes mellitus was defined as fasting plasma glucose $\geq 6.93 \mathrm{mmol} / \mathrm{l}(\geq 1260 \mathrm{mg} / \mathrm{l})$. Dyslipidaemia was defined as having hypertriacylglycerolaemia $(\geq 2.2 \mathrm{mmol} / \mathrm{l}$ or $2000 \mathrm{mg} / \mathrm{l})$ or hypercholesterolaemia $(\geq 6.24 \mathrm{mmol} / \mathrm{l}$ or $2400 \mathrm{mg} / \mathrm{l})$ or high LDL-cholesterol $(\geq 4.1 \mathrm{mmol} / \mathrm{l}$ or $1600 \mathrm{mg} / \mathrm{l})$ or low HDL-cholesterol $(<1.29 \mathrm{mmol} / \mathrm{l}$ or $500 \mathrm{mg} / \mathrm{l})$. Hypertension was defined as systolic blood pressure $\geq 140 \mathrm{mmHg}$ or diastolic blood pressure $\geq 90 \mathrm{mmHg}$. The presence of 'at least one risk factor' and 'at least two risk factors' was defined as having one or two risk factors from among the three major risk factors for CVD (hypertension, dyslipidaemia and diabetes), respectively.

† PHVO (commonly used for cooking in Iran) was considered as the PHVO category. Sunflower oil, maize oil, rapeseed oil, soyabean oil and olive oil were defined as the non-HVO category.

$\mp \chi^{2}$ test.

high consumption of $\mathrm{HVO}$ was associated with a greater risk of having dyslipidaemia (OR for top $v$. bottom quintile 5.04; 95\% CI 2.70, 9.36), hypertension (OR for top $v$. bottom quintile 3.03 ; $95 \%$ CI $1.55,6 \cdot 10)$, at least one (OR for top $v$. bottom quintile $8.52 ; 95 \%$ CI $4.41,16 \cdot 41$ ) and at least two risk factors (OR for top $v$. bottom quintile 3.60; $95 \%$ CI 1.64, 7.74), while those in the top quintile of non-HVO consumption had lower odds for all these conditions. Further adjustment for dietary intakes had little impact on these associations. Even after additional adjustment for BMI, the positive association of HVO and the inverse association of non-HVO consumption with the above-mentioned cardiovascular risk factors remained significant, except for the association between non-HVO consumption and hypertension that became marginally significant. No overall significant associations were found between consumption of HVO and non-HVO and diabetes.

\section{Discussion}

We observed a significant association between the consumption of PHVO and individual cardiovascular risk factors among a group of women in Iran. In contrast, non-HVO were inversely associated with cardiovascular risk factors. The mentioned associations persisted in the multivariate models accounting for known potential confounders.

The process of hydrogenation of vegetable oils, which prolongs the shelf life and alters the physical characteristics of vegetable oils, dates back to earlier findings about the detrimental effects of animal fat intake on human health $^{(29,30)}$. Subsequently, several investigators reported that hydrogenation results in greater amounts of TFA in $\mathrm{HVO}^{(31)}$. Higher intakes of TFA have been associated with an elevated risk of many chronic diseases ${ }^{(32)}$. This is why the regulatory agencies in the USA and some European countries ruled the appearance of the TFA content of packaged foods on the Nutrition Facts panel ${ }^{(5)}$. Although trans-fats occur in natural foods such as meat and dairy products, consumption of trans-fats in these products typically contributes less than $0.5 \%$ of total energy intake ${ }^{(32)}$. It seems that major dietary sources of trans-fats are industrially produced ones, particularly $\mathrm{PHVO}^{(33)}$. Until recently, PHVO were extensively used in Iran, probably due to governmental subsidy. However, due to adverse health effects of trans-fats on human health, the government has now changed its subsidy to non-HVO ${ }^{(33)}$

Although earlier studies on Western populations have indicated the significant association of trans-fats and CHD risk $^{(5,7)}$, limited data in this regard are available in developing countries. This is particularly important to consider as trans-fats contribute to a higher percentage of energy in developing countries as compared with developed nations $^{(11)}$. In a case-control study in India, an elevated risk of IHD has been shown by vanaspati consumption which contains higher amounts of trans-fats ${ }^{(34)}$. In Iran, based on the relationships of TFA intake with CHD incidence in prospective studies, it has been estimated that $19 \%$ of CHD events would be prevented by half-reduction and $34 \%$ would be prevented by near-elimination of TFA intake $^{(11)}$. In Costa Rica, a positive significant association has been reported between elevated levels of TFA in adipose tissue and the risk of non-fatal acute myocardial infarction $^{(35)}$. However, the investigators failed to find a significant relationship between adipose tissue TFA levels and the increased risk of myocardial infarction after the industrial modification, which resulted in the reduction of TFA in the food supply of this population ${ }^{(36)}$. The lack of an association between low levels of trans-fat intake and serum lipids has also been documented by others ${ }^{(37,38)}$ However, these findings, which are in contrast to ours, should not lead to a safe recommendation of trans-fat intake, because the findings of these studies were either based on individual trans-fats (rather than total trans-fats) or on the use of adipose tissue levels (rather than their intake). Totally, data on TFA consumption in developing countries are limited. However, it seems that PHVO are extensively used for cooking in these countries, making TFA contribution to total energy intake much greater than 
Table 3. Crude and multivariate-adjusted OR $(95 \% \mathrm{Cl})$ for cardiovascular risk factors in Iranian women across quintiles of partially hydrogenated and non-hydrogenated vegetable oils* (Odds ratios and $95 \%$ confidence intervals)

\begin{tabular}{|c|c|c|c|c|c|c|c|c|c|c|c|c|c|c|c|c|c|c|c|c|}
\hline & \multicolumn{9}{|c|}{ Partially hydrogenated vegetable oil quintiles } & \multirow{2}{*}{$\begin{array}{l}P \text { for } \\
\text { trend\|l }\end{array}$} & \multicolumn{9}{|c|}{ Non-hydrogenated vegetable oil quintiles } & \multirow[b]{2}{*}{$\begin{array}{l}P \text { for } \\
\text { trend\|l }\end{array}$} \\
\hline & $1(n 97)$ & \multicolumn{2}{|c|}{$2(n 97)$} & \multicolumn{2}{|c|}{$3(n 97)$} & \multicolumn{2}{|c|}{$4(n 98)$} & \multicolumn{2}{|r|}{$5(n 97)$} & & $1(n 97)$ & \multicolumn{2}{|c|}{$2(n 97)$} & \multicolumn{2}{|c|}{$3(n 98)$} & \multicolumn{2}{|c|}{$4(n 97)$} & \multicolumn{2}{|r|}{$5(n 97)$} & \\
\hline \multicolumn{21}{|l|}{ Diabetes } \\
\hline Crude & 1.00 & 1.70 & $0 \cdot 39,7 \cdot 33$ & 2.06 & $0.63,6.75$ & 2.04 & $0.49,8.41$ & 2.43 & $0.61,9 \cdot 71$ & 0.27 & 1.00 & 0.64 & $0.22,1 \cdot 88$ & 0.52 & $0.16,1 \cdot 62$ & 0.31 & $0.08,1 \cdot 18$ & 0.42 & $0.12,1 \cdot 41$ & 0.37 \\
\hline Model $1 \dagger$ & 1.00 & 1.68 & $0 \cdot 46,7 \cdot 28$ & 2.05 & $0.65,6.69$ & 2.03 & $0.47,8.33$ & $2 \cdot 38$ & $0.58,9.65$ & 0.35 & 1.00 & 0.66 & $0 \cdot 25,1 \cdot 81$ & 0.54 & $0.19,1.65$ & 0.35 & $0 \cdot 11,1 \cdot 15$ & 0.50 & $0.15,1.47$ & 0.30 \\
\hline Model $2 \ddagger$ & 1.00 & 1.70 & $0.50,7 \cdot 17$ & 2.03 & $0.64,6.65$ & 2.06 & $0.41,8.19$ & 2.35 & $0.60,9.53$ & 0.19 & 1.00 & 0.67 & $0.20,1.74$ & 0.55 & $0.15,1.57$ & 0.39 & $0.08,1 \cdot 10$ & 0.53 & $0.13,1.39$ & 0.26 \\
\hline Model $3 \S$ & 1.00 & 1.64 & $0.53,7 \cdot 10$ & 2.04 & $0.60,6.58$ & 1.92 & $0.44,8.14$ & $2 \cdot 11$ & $0.55,9.47$ & 0.2 & 1.00 & 0.64 & $0.17,1.69$ & 0.49 & $0.12,1 \cdot 64$ & 0.32 & $0 \cdot 10,1 \cdot 14$ & 0.51 & $0 \cdot 10,1 \cdot 51$ & 0.29 \\
\hline \multicolumn{21}{|c|}{ Dyslipidaemia } \\
\hline Crude & 1.00 & 1.77 & $0.96,3.27$ & $2 \cdot 29$ & $1 \cdot 25,4 \cdot 20$ & 3.53 & $1.93,6.46$ & $5 \cdot 10$ & $2 \cdot 75,9.44$ & 0.001 & 1.00 & 0.84 & $0.47,1.49$ & 0.63 & $0.35,1 \cdot 11$ & 0.34 & $0.19,0.62$ & 0.27 & $0.15,0.49$ & 0.001 \\
\hline Model $1 \dagger$ & 1.00 & 1.72 & $0.94,3.25$ & $2 \cdot 28$ & $1 \cdot 19,4 \cdot 23$ & 3.44 & $1.88,6 \cdot 34$ & 5.04 & $2 \cdot 70,9 \cdot 36$ & 0.001 & 1.00 & 0.89 & $0.50,1.43$ & 0.67 & $0.36,1.08$ & 0.35 & $0.22,0.68$ & 0.35 & $0.18,0.56$ & 0.02 \\
\hline Model 2‡ & 1.00 & 1.74 & $0.97,3.20$ & $2 \cdot 28$ & $1 \cdot 18,4 \cdot 19$ & 3.38 & $1 \cdot 70,6 \cdot 14$ & 4.97 & $2 \cdot 61,9 \cdot 21$ & 0.001 & 1.00 & 0.88 & $0.42,1.37$ & 0.69 & $0 \cdot 30,1 \cdot 18$ & 0.41 & $0.20,0.72$ & 0.39 & $0.22,0.59$ & 0.02 \\
\hline Model 3§ & 1.00 & 1.66 & $0.98,3.11$ & $2 \cdot 26$ & $1 \cdot 15,4 \cdot 20$ & 3.17 & $1.61,6.04$ & 4.68 & $2.52,9 \cdot 17$ & 0.001 & 1.00 & 0.84 & $0.36,1.28$ & 0.63 & $0.33,1.23$ & 0.33 & $0.24,0.77$ & 0.37 & $0.27,0.67$ & 0.02 \\
\hline \multicolumn{21}{|l|}{ Hypertension } \\
\hline Crude & 1.00 & 1.66 & $0.82,3.37$ & 1.75 & $0.87,3.55$ & 2.02 & $1.01,4.04$ & 3.12 & $1 \cdot 58,6 \cdot 13$ & 0.001 & 1.00 & 1.00 & $0.54,1.81$ & 0.73 & $0.39,1.35$ & 0.59 & $0.31,1 \cdot 12$ & 0.46 & $0.23,0.89$ & 0.004 \\
\hline Model $1 \dagger$ & 1.00 & 1.66 & $0.80,3.33$ & 1.73 & $0.89,3.51$ & 1.98 & $1.03,3.96$ & 3.03 & $1 \cdot 55,6 \cdot 10$ & 0.008 & 1.00 & 1.04 & $0.51,1.73$ & 0.73 & $0.42,1 \cdot 31$ & 0.62 & $0.29,1.06$ & 0.51 & $0.25,0.91$ & 0.01 \\
\hline Model 2‡ & 1.00 & 1.69 & $0.86,3.27$ & 1.74 & $0.88,3.54$ & 1.95 & $0.96,3.88$ & 2.96 & $1.57,6.04$ & 0.01 & 1.00 & 1.06 & $0.53,1.77$ & 0.75 & & 0.66 & $0.36,1.08$ & 0.55 & $0.31,0.95$ & 0.04 \\
\hline Model $3 \S$ & 1.00 & 1.61 & $0.90,3.19$ & 1.72 & $0.92,3.48$ & 1.84 & $0.87,3.81$ & 2.69 & $1.51,5.98$ & $0 . c$ & 1.0 & 1.03 & $0.47,1.71$ & 0.70 & $0.37,1.33$ & 0.59 & $0.31,1.03$ & 0.52 & $0.37,1.04$ & 0.10 \\
\hline \multicolumn{21}{|c|}{ At least one risk factor } \\
\hline Crude & 1.00 & 1.43 & $0.79,2 \cdot 60$ & 2.47 & $1.37,4.45$ & 3.84 & $2.12,6.97$ & 8.59 & $4.47,16.53$ & 0.001 & 1.00 & 0.91 & $0.50,1.65$ & 0.57 & $0.32,1.03$ & 0.32 & $0.18,0.59$ & 0.25 & $0.13,0.46$ & 0.003 \\
\hline Model $1 \dagger$ & 1.00 & 1.41 & $0.83,2.51$ & 2.44 & $1.41,4.37$ & 3.77 & $2.07,6.90$ & 8.52 & $4.41,16.41$ & 0.001 & 1.00 & 0.94 & $0.44,1.57$ & 0.59 & $0.37,1 \cdot 11$ & 0.35 & $0.20,0.62$ & 0.29 & $0.17,0.50$ & 0.009 \\
\hline Model $2 \ddagger$ & & 1.42 & $0.87,2.46$ & 2.42 & & 3.69 & & 8.44 & & & & 0.92 & $0.48,1.51$ & 0.63 & $0.31,1 \cdot 10$ & 0.42 & $0.25,0.69$ & 0.32 & $0.21,0.56$ & 0.01 \\
\hline Model $3 \S$ & 1.00 & 1.37 & $0.85,2.48$ & 2.41 & $1 \cdot 19,4 \cdot 10$ & 3.52 & $1.88,6.71$ & 8.12 & $4 \cdot 24,16 \cdot 17$ & 0.001 & 1.00 & 0.90 & $0.41,1.44$ & 0.56 & $0 \cdot 27,1 \cdot 17$ & 0.34 & $0.23,0.67$ & 0.36 & $0.26,0.67$ & 0.02 \\
\hline \multicolumn{21}{|c|}{ At least two risk factors } \\
\hline Crude & 1.00 & $1 \cdot 10$ & $0.46,2.63$ & 1.66 & $0.73,3.76$ & 2.39 & $1.09,5.24$ & 3.67 & $1.71,7.83$ & 0.001 & 1.00 & 0.67 & $0 \cdot 36,1 \cdot 25$ & 0.33 & $0.16,0.66$ & 0.26 & $0.12,0.54$ & 0.14 & $0.06,0.34$ & 0.001 \\
\hline Model $1 \dagger$ & 1.00 & 1.07 & $0.50,2 \cdot 60$ & 1.64 & $0 \cdot 70,3 \cdot 70$ & $2 \cdot 30$ & $1 \cdot 06,5 \cdot 17$ & 3.60 & $1 \cdot 64,7 \cdot 74$ & 0.003 & 1.00 & 0.70 & $0 \cdot 38,1 \cdot 29$ & 0.39 & $0.14,0 \cdot 70$ & 0.30 & $0.15,0.59$ & 0.20 & $0.10,0.38$ & $00 \cdot 01$ \\
\hline Model 2‡ & 1.00 & $1 \cdot 11$ & $0.52,2.52$ & 1.65 & $0.71,3.61$ & 2.23 & $1.00,5.08$ & 3.55 & $1.59,7.63$ & 0.02 & 1.00 & 0.69 & $0.33,1.25$ & 0.42 & $0.19,0.77$ & 0.39 & $0.18,0.67$ & 0.25 & $0.12,0.41$ & 0.001 \\
\hline Model $3 \S$ & 1.00 & 1.02 & $0.55,2.47$ & 1.62 & $0.64,3.55$ & $2 \cdot 14$ & $0.94,5.01$ & $3 \cdot 27$ & $1.62,7.57$ & 0.02 & 1.00 & 0.66 & $0.30,1.28$ & 0.36 & $0.23,0.82$ & 0.31 & $0.19,0.71$ & 0.21 & $0.19,0.50$ & 0.003 \\
\hline
\end{tabular}

* Diabetes mellitus was defined as fasting plasma glucose $\geq 6.93 \mathrm{mmol} / \mathrm{l}(\geq 1260 \mathrm{mg} / \mathrm{l})$. Dyslipidaemia was defined as having hypertriglyceridaemia $(\geq 2.2 \mathrm{mmol} / \mathrm{l}$ or $2000 \mathrm{mg} / \mathrm{l})$ or hypercholesterolaemia $(\geq 6.24 \mathrm{mmol} / / \mathrm{lor} 240 \mathrm{md} / \mathrm{dl})$
or high $\mathrm{LDL}$-cholesterol $(\geq 4.1 \mathrm{mmo} / / / \mathrm{lor} 1600 \mathrm{mg} / \mathrm{l})$ or low $\mathrm{HDL}$-cholesterol $(<1.29 \mathrm{mmo} / / \mathrm{lor} 500 \mathrm{mg} / \mathrm{l})$. Hypertension was defined as systolic blood pressure $\geq 140 \mathrm{mmHg}$ or diastolic blood pressure $\geq 90 \mathrm{mmHg}$. The presence of 'at least one risk factor' and 'at least two risk factors' was defined as having one or two risk factors from among the three major risk factors for CVD (hypertension, dyslipidaemia and diabetes), respectively.

† Model I: adjusted for the mutual effects of hydrogenated and non-hydrogenated vegetable oils (g/d), age (years), energy intakes (kJ/d), cigarette smoking (yes or no), physical activity (metabolic equivalent-h/week), socio-economic status (categorical), current oestrogen use (yes or no), menopausal status (yes or no) and family history of diabetes and stroke (yes or no).

‡ Model 2: further adjusted for dietary intakes including intakes of cholesterol, fruits and vegetables, whole and refined grains, dairy, meat, fish and poultry (all as continuous).

$\S$ Model 3: additionally controlled for BMI (continuous).

|| Mantel-Haenszel extension $\chi^{2}$ test. 
that in developed countries. Therefore, the findings of the present study are applicable to developing countries with a high intake of TFA. The present results might also be generalisable to other countries with moderate but still higher than the recommended intakes of TFA because previous studies have shown a dose-dependent relationship between TFA intake and the risk of $\mathrm{CHD}^{(5)}$.

In the present study, a higher intake of PHVO was associated with a greater risk of having dyslipidaemia. Although the adverse effects of trans-fats on lipid profiles have extensively been studied in clinical trials, a few observational data have assessed the relationship between habitual consumption of trans-fats and serum lipid levels ${ }^{(39)}$. To have a recommendation for the general population, observational data seem to be more important than clinical trials because most trials have evaluated the short-term effects of higher doses of trans-fat among healthy people, and the effects of habitual trans-fat intake have rarely been investigated. However, it must be kept in mind that associations found in observational studies, particularly those by cross-sectional studies, cannot ever be considered causal, and much evidence from different populations needs to be gathered before making public health recommendations. In a nested prospective study of American women, Sun et al. ${ }^{(40)}$ found that higher erythrocyte trans-fat levels, as a biomarker of dietary intake of trans-fats, are associated with adverse lipid profiles. This finding is in accordance with the results of clinical trials in which isoenergetic replacement of either saturated or cis-unsaturated fats with TFA raised LDL-C and reduced HDL-C ${ }^{(32,39)}$. The effects of a higher trans-fat intake on serum TAG and total cholesterol levels have also been documented ${ }^{(41)}$. Besides trans-fats, individuals with higher intakes of PHVO would have higher intakes of SFA and lower intakes of polyunsaturated fats. A greater SFA intake would result in an increase in plasma total cholesterol and LDL-C levels. Replacing these fatty acids with PUFA would decrease these lipid profiles ${ }^{(42)}$. Therefore, a high prevalence of dyslipidaemia among those with higher intakes of PHVO can also be explained by higher intakes of SFA and simultaneous lower intakes of PUFA. However, due to the limitation in the Iranian food composition table, we were unable to compute the exact dietary intakes of each individual fatty acid in this population.

We found that a higher intake of PHVO was associated with a greater risk of having hypertension, even after controlling for BMI. To the best of our knowledge, the present study is the first observational investigation reporting habitual PHVO intake in relation to blood pressure. Our observational finding is in contrast to what has been reported by clinical trials on the effects of trans-fats on blood pressure. A few trials, which have assessed such an impact, found no significant effects of trans-fat intake on blood pressure in healthy normotensive participants ${ }^{(43)}$. This disagreement in findings can be explained by the short duration and small sample sizes in clinical trials.
Other factors such as the cross-sectional design of the present study and residual confounding might account for this discrepancy. The mechanism by which TFA intake can affect blood pressure is unknown. However, it has been shown that consumption of TFA impaired endothelial function, as reflected by a reduction in brachial artery flow-mediated vasodilatation by $29 \%{ }^{(44)}$. This dysfunction would in turn lead to elevated blood pressure.

We did not find any significant association between consumption of different kinds of vegetable oils, either PHVO or non-HVO, and the prevalence of diabetes, neither before nor after controlling for potential confounders. The finding of no significant association between PHVO and diabetes is in agreement with the studies of van Dam et $a l .{ }^{(45)}$ in the Health Professionals Follow-up Study and Meyer et $a l{ }^{(46)}$ in Iowa. Both mentioned studies have not found significant association between trans-fat intake and incident diabetes. However, Hu et al. ${ }^{(47)}$ found that transfat intake was significantly associated with diabetes incidence. The major findings from clinical trials also suggest that a higher trans-fat intake increases insulin resistance and diabetes risk ${ }^{(48)}$. Our previous investigation among Iranian women also demonstrated that a higher PHVO intake is significantly associated with a greater risk of the metabolic syndrome and insulin resistance, while higher intakes of non-HVO were associated with a lower risk of insulin resistance ${ }^{(16)}$. The lack of a significant association between vegetable oils and diabetes in the present study needs further investigation. The possible reasons for this finding might be a lower prevalence of diabetes as compared with other cardiovascular risks, inadequate sample size and the cross-sectional design of the study.

Several limitations need to be considered in the interpretation of the present findings. The major limitation of the present study is its cross-sectional nature. Thus, the association between HVO consumption and cardiovascular risk factors in the Iranian population remains to be confirmed in prospective analyses. We have only considered the in-home consumption of HVO and non-HVO. This would probably underestimate the total intake and would affect the associations we studied in this population. As we used a FFQ for assessing dietary intakes, misclassification is a major concern in the present study as in any other epidemiological studies. The present study includes only women. It seems that Iranian women are at a greater risk of CVD as compared with men.

In conclusion, the present findings suggest that higher intakes of PHVO were associated with a greater risk of having cardiovascular risk factors, while higher intakes of non-HVO were associated with a lower risk of these conditions.

\section{Acknowledgements}

The data collection phase of the study was supported by a grant (P. 25/47/2337) from the National Nutrition and Food 
Technology Research Institute of the Islamic Republic of Iran and Shaheed Beheshti University of Medical Sciences, Tehran, Iran. The financial support for conception, design, data analysis and manuscript drafting comes from School of Public Health, Isfahan University of Medical Sciences, Isfahan, Iran. We thank the participants of the study for their enthusiastic support. None of the authors had any personal or financial conflicts of interest. A. E. and L. A. participated in the collection of data, conception and design, statistical analysis and data interpretation, manuscript drafting and approval of the final manuscript for submission.

\section{References}

1. Okrainec K, Banerjee DK \& Eisenberg MJ (2004) Coronary artery disease in the developing world. Am Heart $J \mathbf{1 4 8}$ $7-15$.

2. Yusuf S, Hawken S, Ounpuu S, et al. (2004) Effect of potentially modifiable risk factors associated with myocardial infarction in 52 countries (the INTERHEART study): casecontrol study. Lancet 364, 937-952.

3. Yusuf S, Reddy S, Ounpuu S, et al. (2001) Global burden of cardiovascular diseases: part II: variations in cardiovascular disease by specific ethnic groups and geographic regions and prevention strategies. Circulation 104, 2855-2864.

4. Reddy KS \& Yusuf S (1998) Emerging epidemic of cardiovascular disease in developing countries. Circulation 97, 596-601.

5. Mozaffarian D, Katan MB, Ascherio A, et al. (2006) Trans fatty acids and cardiovascular disease. $N$ Engl J Med 354, 1601-1613.

6. Chardigny JM, Malpuech-Brugere C, Dionisi F, et al. (2006) Rationale and design of the TRANSFACT project phase I: a study to assess the effect of the two different dietary sources of trans fatty acids on cardiovascular risk factors in humans. Contemp Clin Trials 27, 364-373.

7. Lichtenstein AH, Ausman LM, Jalbert SM, et al. (1999) Effects of different forms of dietary hydrogenated fats on serum lipoprotein cholesterol levels. N Engl J Med 340, 1933-1940.

8. Judd JT, Baer DJ, Clevidence BA, et al. (2002) Dietary cis and trans monounsaturated and saturated FA and plasma lipids and lipoproteins in men. Lipids 37, 123-131.

9. Oomen CM, Ocke MC, Feskens EJ, et al. (2001) Association between trans fatty acid intake and 10-year risk of coronary heart disease in the Zutphen Elderly Study: a prospective population-based study. Lancet 357, 746-751.

10. Pisabarro RE, Sanguinetti C, Stoll M, et al. (2004) High incidence of type 2 diabetes in peroxisome proliferator-activated receptor gamma2 Pro12Ala carriers exposed to a high chronic intake of trans fatty acids and saturated fatty acids. Diabetes Care 27, 2251-2252.

11. Mozaffarian D, Abdollahi M, Campos H, et al. (2007) Consumption of trans-fats and estimated effects on coronary heart disease in Iran. Eur J Clin Nutr 61, 1004-1010.

12. Asgary S, Nazari B, Sarrafzadegan S, et al. (2009) Fatty acid composition of commercially available Iranian vegetable oils. J Res Med Sci 14, 211-215.

13. Azizi F, Esmaillzadeh A \& Mirmiran P (2004) Obesity and cardiovascular disease risk factors in Tehran adults: a population-based study. East Mediterr Health J 10, 887-897.

14. Esmaillzadeh A \& Azadbakht L (2008) Food intake patterns may explain the high prevalence of cardiovascular risk factors among Iranian women. J Nutr 138, 1469-1475.
15. Esmaillzadeh A \& Azadbakht L (2008) Home use of vegetable oils, markers of systemic inflammation and endothelial dysfunction among women. Am J Clin Nutr 88, 913-921.

16. Esmaillzadeh A \& Azadbakht L (2008) Consumption of hydrogenated versus non-hydrogenated vegetable oils and risk of insulin resistance and the metabolic syndrome among Iranian adult women. Diabetes Care 31, 223-226.

17. Esmaillzadeh A, Kimiagar M, Mehrabi Y, et al. (2007) Dietary patterns, insulin resistance, and prevalence of the metabolic syndrome in women. Am J Clin Nutr 85, 910-918.

18. Esmaillzadeh A, Kimiagar M, Mehrabi Y, et al. (2006) Fruit and vegetable intakes, C-reactive protein, and the metabolic syndrome. Am J Clin Nutr 84, 1489-1497.

19. Esmaillzadeh A \& Azadbakht L (2008) Major dietary patterns in relation to general obesity and central adiposity among Iranian women. J Nutr 138, 358-363.

20. Ghaffarpour M, Houshiar-Rad A \& Kianfar A (1999) The Manual for Household Measures, Cooking Yields Factors and Edible Portion of Foods (in Farsi). Tehran: Keshavarzi Press.

21. Azadbakht L, Atabak S \& Esmaillzadeh A (2008) Soy protein intake, cardio-renal indices and C-reactive protein in type 2 diabetes with nephropathy: a longitudinal randomized clinical trial. Diabetes Care 3, 648-654.

22. Friedewald WT, Levy RI \& Fredrickson DS (1972) Estimation of the concentration of low-density lipoprotein cholesterol in plasma, without use of the preparative ultracentrifuge. Clin Chem 18, 499-502.

23. National Cholesterol Education Program (NCEP) Expert Panel on Detection, Evaluation, and Treatment of High Blood Cholesterol in Adults (Adult Treatment Panel III) (2002) Third report of the National Cholesterol Education Program (NCEP) Expert Panel on detection, evaluation, and treatment of high blood cholesterol in adults. Circulation 106, 3143-421.

24. Joint National Committee on Prevention, Detection, Evaluation and Treatment of High Blood Pressure (1997) The sixth report of the Joint National Committee on prevention, detection, evaluation and treatment of high blood pressure. Arch Intern Med 157, 2413-46.

25. Expert Committee on the Diagnosis and Classification of Diabetes Mellitus (2003) Report of the Expert Committee on the diagnosis and classification of diabetes mellitus. Diabetes Care 26, S5-S20.

26. Esmaillzadeh A, Kimiagar M, Mehrabi Y, et al. (2007) Dietary patterns and markers of systemic inflammation among Iranian women. J Nutr 137, 992-998.

27. Craig CL, Marshall AL, Sjostrom M, et al. (2003) International physical activity questionnaire: 12-country reliability and validity. Med Sci Sports Exerc 35, 1381-1395.

28. Willett WC (1998) Nutritional Epidemiology, 2nd ed. New York: Oxford University Press.

29. McGandy RB, Hegsted DM \& Myers ML (1970) Use of semisynthetic fats in determining effects of specific dietary fatty acids on serum lipids in man. Am J Clin Nutr 23, 1288-1298.

30. Keys A, Anderson JT \& Grande F (1965) Serum cholesterol response to change in the diet. Metabolism 14, 747-758.

31. Lichtenstein AH, Ausman LM, Carrasco W, et al. (1993) Hydrogenation impairs the hypolipidemic effect of corn oil in humans: hydrogenation, trans fatty acids, and plasma lipids. Arterioscler Thromb 13, 154-161.

32. Micha R \& Mozaffarian D (2008) Trans fatty acids: effects on cardiometabolic health and implications for policy. Prostaglandins Leukot Essent Fatty Acids 79, 147-152.

33. Azadbakht L \& Esmaillzadeh A (2008) Fast foods and risk of chronic diseases. J Res Med Sci 13, 1-2. 
34. Rastogi T, Reddy KS, Vaz M, et al. (2004) Diet and risk of ischemic heart disease in India. Am J Clin Nutr 79, 582-592.

35. Baylin A, Kabagambe EK, Ascherio A, et al. (2003) High 18:2 trans-fatty acids in adipose tissue are associated with increased risk of nonfatal acute myocardial infarction in Costa Rican adults. J Nutr 133, 1186-1191.

36. Colón-Ramos U, Baylin A \& Campos H (2006) The relation between trans fatty acid levels and increased risk of myocardial infarction does not hold at lower levels of trans fatty acids in the Costa Rican food supply. J Nutr 136, 2887-2892.

37. Aro A, Kardinaal AF, Salminen I, et al. (1995) Adipose tissue isomeric trans fatty acids and risk of myocardial infarction in nine countries: the EURAMIC study. Lancet 345, 273-278.

38. Roberts TL, Wood DA, Riemersma RA, et al. (1995) Trans isomers of oleic and linoleic acids in adipose tissue and sudden cardiac death. Lancet 345, 278-282.

39. Mozaffarian D, Aro A \& Willett WC (2009) Health effects of trans-fatty acids: experimental and observational evidence. Eur J Clin Nutr 63, S5-S21.

40. Sun Q, Ma J, Campos H, et al. (2007) A prospective study of trans fatty acids in erythrocytes and risk of coronary heart disease. Circulation 115, 1858-1865.

41. Mozaffarian D \& Clarke R (2009) Quantitative effects on cardiovascular risk factors and coronary heart disease risk of replacing partially hydrogenated vegetable oils with other fats and oils. Eur J Clin Nutr 63, S22-S33.
42. Grundy SM \& Denke MA (1990) Dietary influences on serum lipids and lipoproteins. J Lipid Res 31, 1149-1172.

43. European Food Safety Authority (2004) Opinion of the scientific panel on dietetic products, nutrition and allergies on a request from the commission related to the presence of trans fatty acids in foods and the effect on human health of the consumption of trans fatty acids. EFSA J 81, 1-49.

44. Roos NM, Bots ML \& Katan MB (2001) Replacement of dietary saturated fatty acids by trans fatty acids lowers serum HDL cholesterol and impairs endothelial function in healthy men and women. Arterioscler Thromb Vasc Biol 21, $1233-1237$.

45. van Dam RM, Rimm EB, Willett WC, et al. (2002) Dietary patterns and risk for type 2 diabetes mellitus among US men. Ann Intern Med 136, 201-209.

46. Meyer KA, Kushi LH, Jacobs DR Jr, et al. (2001) Dietary fat and incidence of type 2 diabetes in older Iowa women. Diabetes Care 24, 1528-1535.

47. Hu FB, Manson JE, Stampfer MJ, et al. (2001) Diet, lifestyle, and the risk of type 2 diabetes mellitus in women. $N$ Engl J Med 345, 790-797.

48. Vega-Lopez S, Ausman LM, Jalbert SM, et al. (2006) Palm and partially hydrogenated soybean oils adversely alter lipoprotein profiles compared with soybean and canola oils in moderately hyperlipidemic subjects. Am J Clin Nutr $\mathbf{8 4}, 54-62$ 